\title{
OBSERVATION OF A DIRECTED RESONANCE IN SOIL DRIVEN BY TRANSVERSE ROCK MOTION
}

\author{
W.R. Stephenson ${ }^{1}$
}

\begin{abstract}
One component of horizontal ground acceleration recorded on flexible soil during the 1968 November 1 Cook strait earthquake is shown to be well modelled as a single degree of freedom oscillator excited by the recorded component of transverse acceleration in nearby bed rock.
\end{abstract}

This is shown to be consistent with the cellular resonant mode hypothesis of seismic response of flexible soil.

The mechanical oscillator is identified as a layer of fine-grained, postglacial alluvium of approximately $20 \mathrm{~m}$ thickness.

\section{INTRODUCTION}

The modelling of the motion of deposits of flexible soil under earthquake excitation is a task of considerable practical importance. During the september 1985 Michoacan earthquake, for example, the flexible soils underlying Mexico City, $300 \mathrm{~km}$ from the epicentre, amplified some frequencies of vibration, ultimately leading to the collapse of 250 tall buildings [1].

Stephenson [2] suggested that shallow deposits of flexible soil resonate in "cells", with each cell involving horizontal surface motion along fluid flow lines. Later work [3] used a mathematical model of a system consisting of a cylindrical cavity in a stiff medium to demonstrate that cellular modes are excited by incident, horizontal rock motion in the plane of the wave fronts.

Strong motion earthquake accelerograms recorded on flexible soil show that the acceleration is largely horizontal. Powerspectrum analysis of horizontal accelerations [2] may be used to show that the resonant motion is usually in a single direction. Hence, only horizontal soil motion in the resonant direction need be used to test models of flexible soil.

This paper describes the use of the model derived earlier [3] to predict that, for such a resonant ground response, the direction of the drive component is related to the propagation of waves in the surrounding rock, and that the direction of the response component is related to the topology of the soil/rock boundary.

1 Division of Land and Soil Sciences, DSIR.
An equivalent resonator driven along one direction and responding along another is consistent with a cellular mode response, and allows normal mode responses to be used to explain the behaviour of soil deposits under earthquake excitation.

The Cook strait earthquake of 1968 November 1 generated strong motion accelerograms at two stations $300 \mathrm{~m}$ apart in the lower Hutt Valley, one on rock (at the Institute of Nuclear Sciences, D.S.I.R.) and the other on soil (at Physics and Engineering Laboratory, D.S.I.R.). This pair of records is used to test a linear singledegree-of-freedom model by generating a pattern of vibration with time from the accelerogram recorded on rock. The generated pattern is then shown to be very similar to the accelerogram recorded on soil.

This paper uses three concepts ("radial direction", "transverse direction" and "resonant direction") which relate directions in the horizontal plane to physical realities of earthquake propagation and of ground motion response. Each direction has an associated component of ground motion: "radial direction" and "transverse direction" are given with respect to a line joining the epicentre to the measurement site on the flexible soil, as shown in Fig. 1. The transverse direction as used in this paper lies in the plane of wave fronts. It is noted that published records of strong motion often give transverse and longitudinal components with reference to instrument axes.

After examining power spectral analyses of ground motion of flexible soil for records of strong earthquakes, stephenson [2] used "resonant direction" to refer to the direction along which most of the resonant 


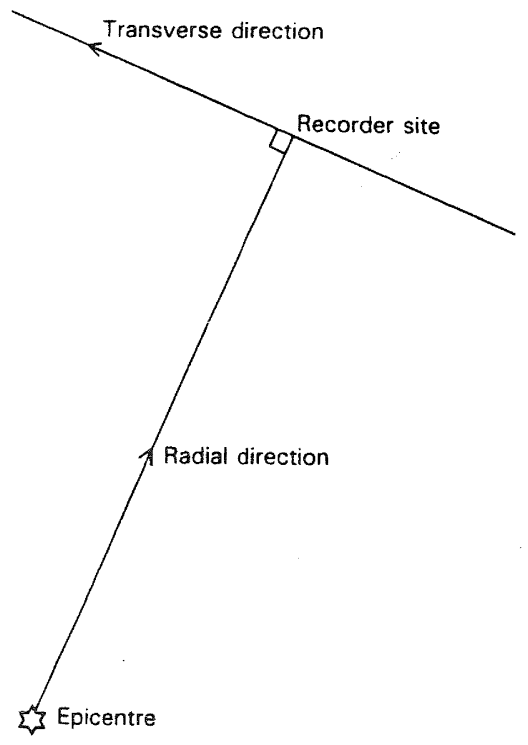

FIG. 1. NOMENCLATURE USED FOR DIRECTIONS.

motion occurs.

Stephenson [2] has shown that the resonant direction is readily calculated from the heights of the resonant peaks on the power spectra of the recorded components, and the height of the resonant peak on the crosspower spectrum between the recorded components.

\section{THE GEOLOGICAL SETTING}

Stevens [4], [5], [6] describes the origin and characteristics of the materials above bedrock in the lower Hutt valley. Coarse alluvial gravels were deposited during glacial times, and subsequently, deltaic deposits were built up as the Hutt River encountered higher sea levels. The deltaic deposits are usually fine grained at depth. Nearer the surface they are coarser and may contain inclusions of boulder-size materials left by meanders of the Hutt River. Seismic cone penetration tests (CPT) (Robertson et al. [7]) carried out by Stephenson and Barker [8] near the Hutt River estuary revealed a change of material at $12.6 \mathrm{~m}$, shown by a decrease in tip resistance and an increase in friction ratio. This is interpreted as an increase in the relative amount of fine-grained material [9] and probably coincides with the change from Taita alluvium to Petone marine silts and clays.

Figs. 2 and 3 show stevens' interpretation of the geology of the Hutt valley. Fig. 4 shows stephenson and Barker's penetrometer results and the log of a nearby Hutt valley Underground Water Authority bore.

The resonant element is expected to be a veneer of flexible material, tapering in depth up valley, being somewhat deeper in the west, and having a depth of some $20 \mathrm{~m}$ at the Hutt estuary. Using the shear wave propagation velocity $(179 \mathrm{~m} / \mathrm{s})$ and depth $(22.4 \mathrm{~m})$ at the CPT probe site, a fundamental mode frequency of $2.0 \mathrm{~Hz}$ is expected for such a veneer if it is of constant depth and infinite extent.

Local inclusions of bouldery material are expected to move bodily with the flexible layer during excitation of a resonant mode. Provided that the total volume of such material is a small fraction of the flexible material, it is the properties of the latter which should dominate.

\section{THE PROPOSED MODEI}

The model predicting the way in which rock motion is transformed into soil motion for the 1968 November 1 earthquake is based on the thin extended layer of soft material in the lower Hutt valley together with its lateral boundaries at the rock, the formal modal solutions of Stephenson [3] together with their manner of excitation, and the observed resonant directions and correlations of stephenson [2].

It is assumed that the veneer of flexible soil responded to excitation with a horizontal oscillating fluid flow in the same way as the cylinder of stephenson [3]. Horizontal boundaries corresponding to the cylinder's curved wall are assumed to have been formed by outcropping bed rock, and possibly by a sudden change in the thickness of the flexible veneer. It is known (Stephenson [2]) that there was a peak in the power spectrum of soil motion at $2.4 \mathrm{~Hz}$ during the 1968 November 1 earthquake, with a 'resonant direction' of $51^{\circ}$.

The transverse component of the 1968 November 1 earthquake is assumed to have excited this resonance. The locality diagram of Fig. 5 shows how the shear waves in the rock are assumed to have traversed the site, and Fig. 6 indicates very generally the assumed surface soil resonant motion and its relationship to the arriving wavefronts in the base rock.

The resonant direction is $51^{\circ}$, the transverse direction is $76^{\circ}$, and the radial direction $166^{\circ}$ for this earthquake.

\section{THE EXPERIMENTAL TEST}

If the rock motion at $76^{\circ}$ excited a linear single-degree-of-freedom resonator, then it should be possible to mathematically convolute the impulse response of the resonator with the rock motion at $76^{\circ}$ and thus to obtain a good approximation to the soil motion at $51^{\circ}$, at least in the resonant band.

A resonant frequency of about $2 \mathrm{~Hz}$ was deduced from the known shear wave velocity and depth of the flexible soil layer, but there was no geotechnical method of obtaining the damping or an accurate value of frequency. However by examining the power spectrum of the recorded resonant soil motion it was possible to obtain 


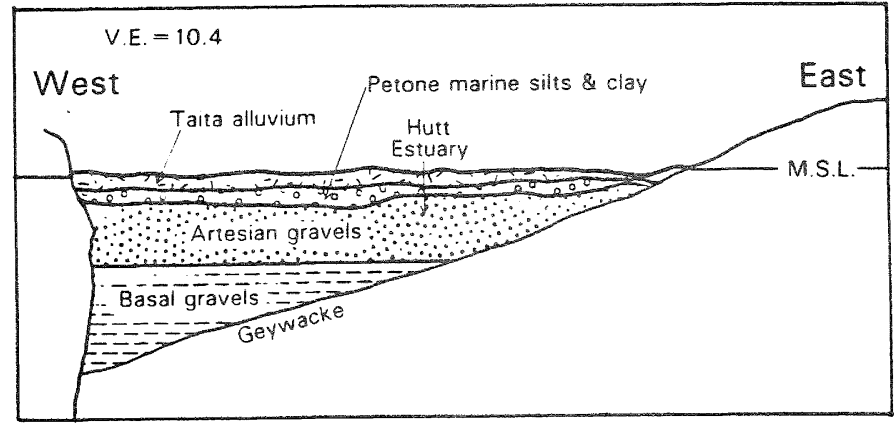

FIG. 2. A GENERALISED SECTION ACROSS THE LOWER HUTT - PORT NICHOLSON BASIN AT PETONE, AFTER STEVENS [6].

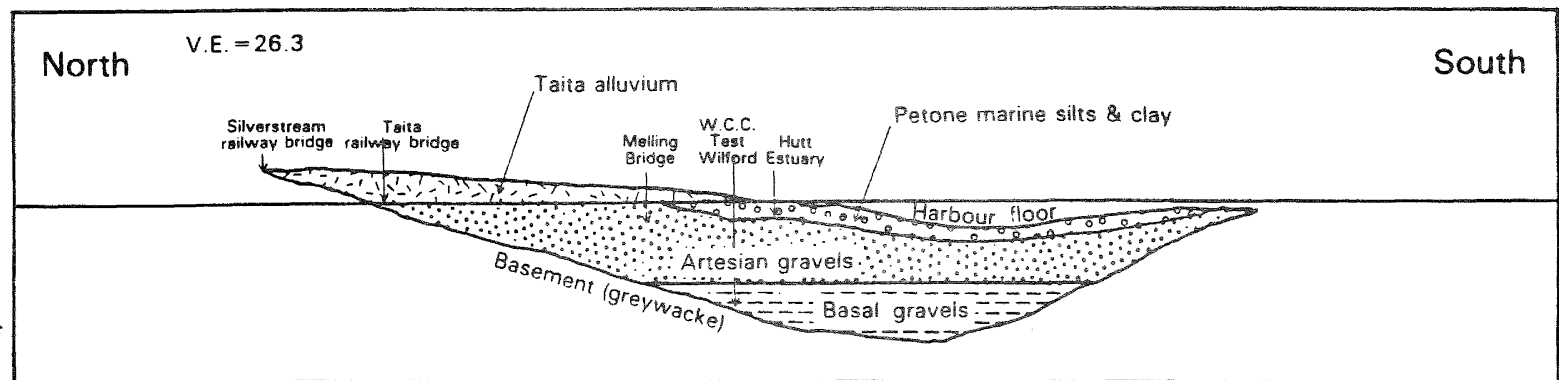

FIG. 3. A GENERALISED LONGITUDINAL SECTION OF THE IOWER HUTT - PORT NICHOLSON BASIN, AFTER STEVENS [6].

Subsurface conditions - Schofield St play area

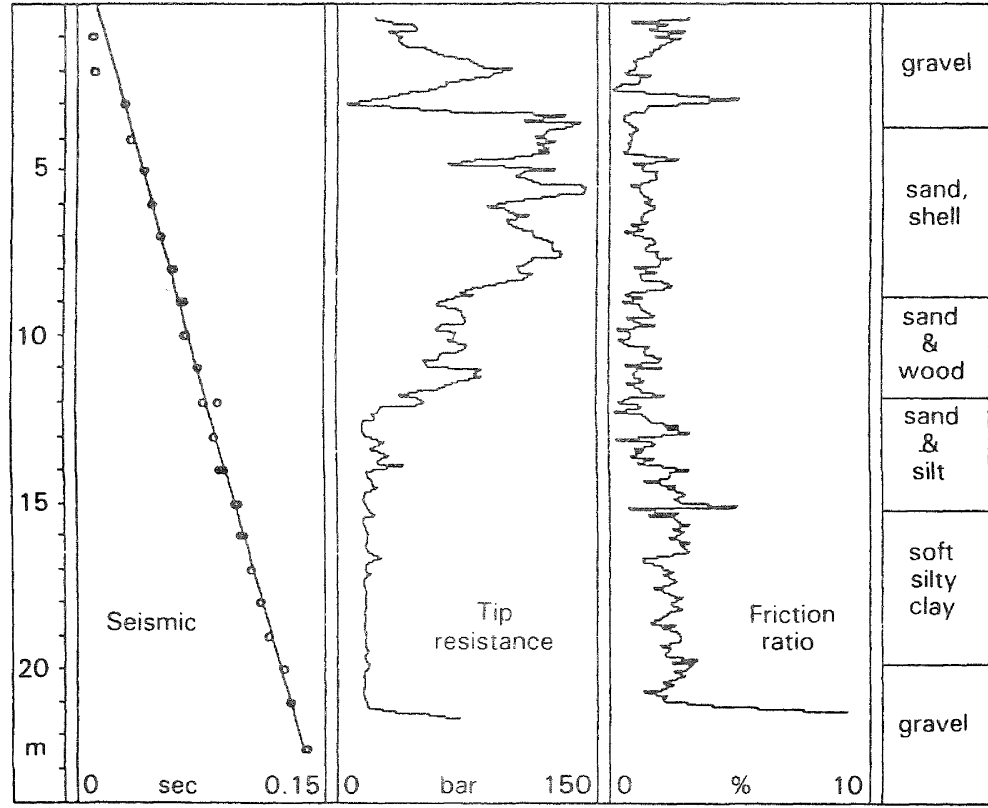

FIG. 4. VARIATION WITH DEPTH OF SEISMIC SHEAR WAVE DELAY, CONE RESISTANCE AND SLEEVE/CONE FRICTION RATIO, FOR A PROBE AT THE SCHOFIELD ST. PLAY AREA. THE BORELOG DESCRIPTIONS REFER TO A BORE AT IEVER BROS FACTORY, SOME 300 M DISTANT. 

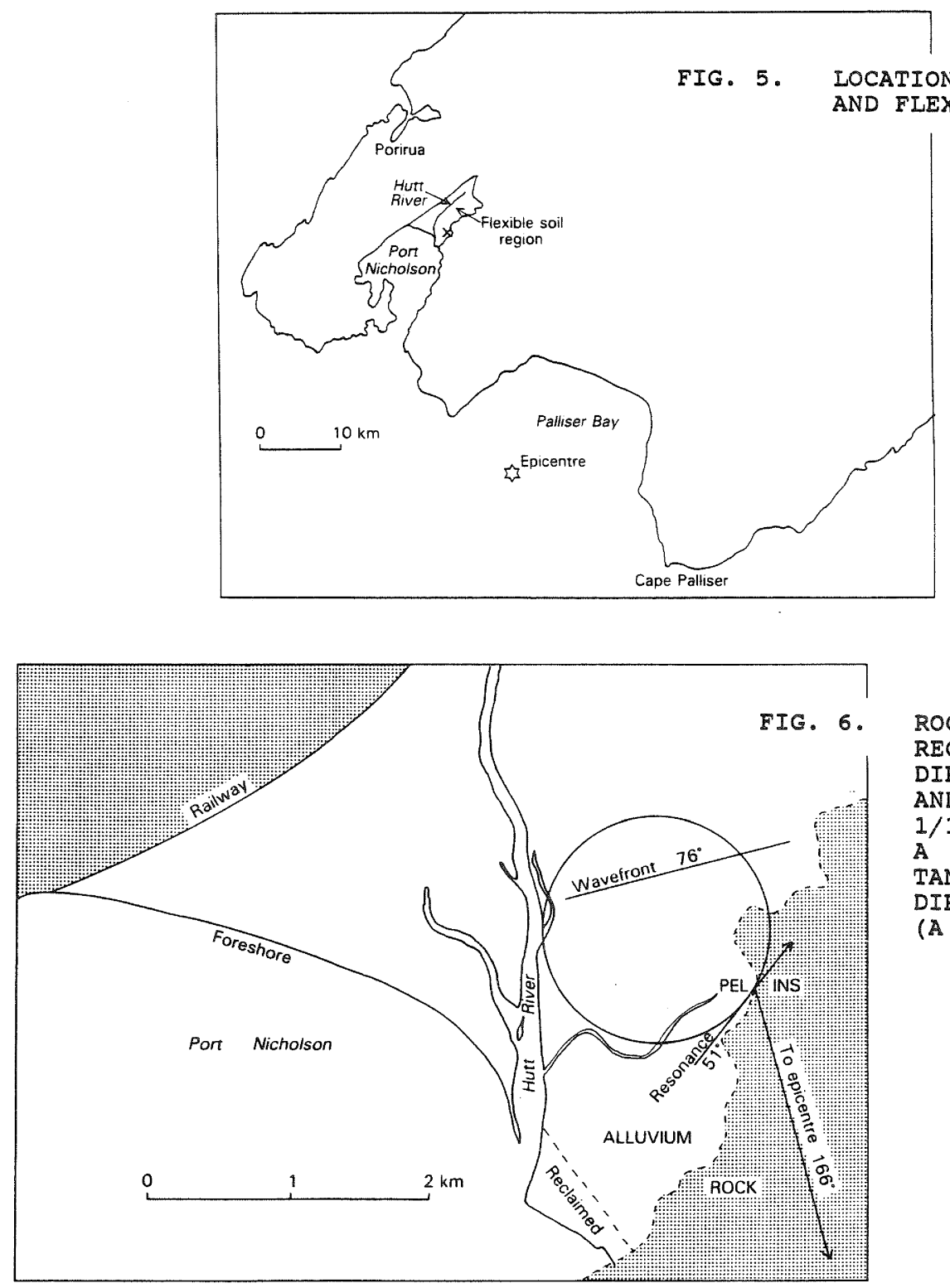

ROCK/ALLUVIUM BOUNDARIES, RECORDING SITES, RESONANCE DIRECTION, EPICENTRAL DIRECTION, AND PLANE OF WAVE FRONTS, FOR THE 1/11/68 COOK STRAIT EARTHQUAKE. A SUGGESTED CYIINDRICAL CELI TANGENT TO THE RESONANCE DIRECTION IS SHOWN AS A CIRCLE (A POSSIBLE "GRACEFIELD CELL").

Soil 51 degrees $-F=2.147, Q=10.39, A=1.573$ - transverse synthesis

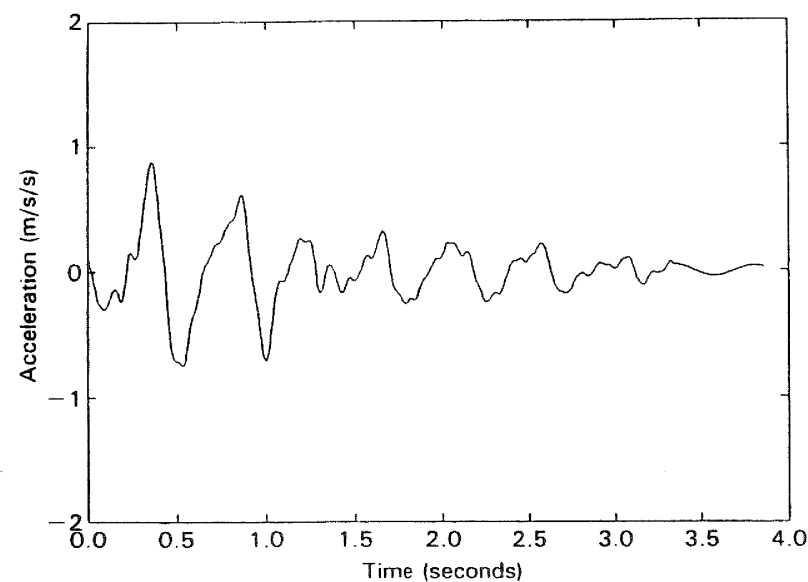

FIG. 7. ACCELERATIONS AT $51^{\circ}$ SYNTHESISED FROM THE RECORDED TRANSVERSE ROCK MOTION FOR A SOIL MODEL WITH FREQUENCY $2.147 \mathrm{HZ}$ Q FACTOR OF 10.39, AND AMPLITUDE FACTOR OF 1.573 .

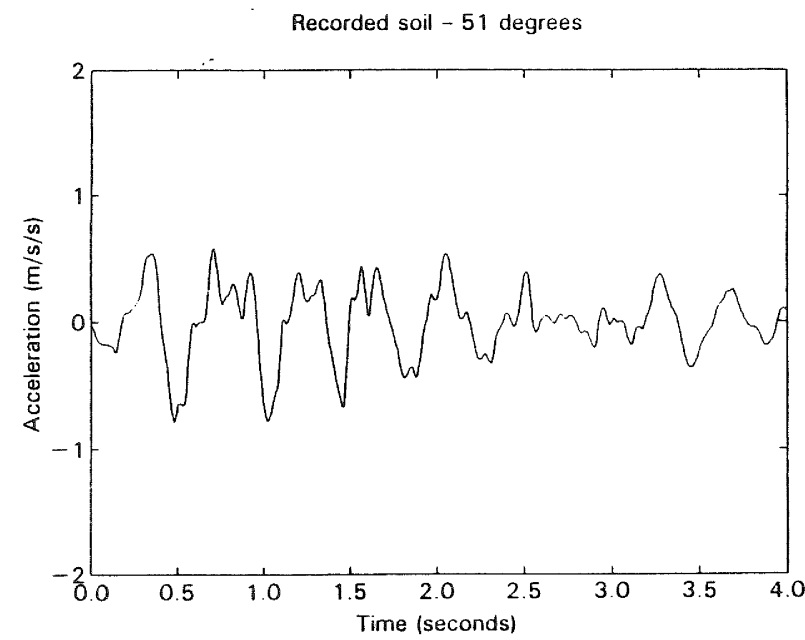

FIG. 8. SOIL ACCELERATION RECORD AT 51 FOR THE $1 / 11 / 68$ EARTHQUAKE. 
Soil 51 degrees $-F=2.147, Q=10.39, A=1.573-$ transverse synthesis

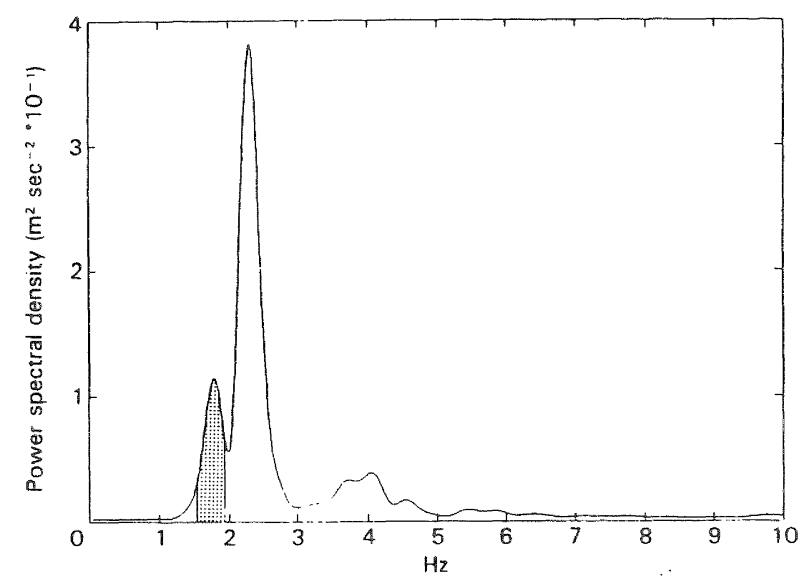

FIG. 9.

SPECTRUM OF SOIL ACCELERATION RECORD AT 51० FOR THE $1 / 11 / 68$ EARTHOUAKE。 THE MARKER PEAK IS SHADED.

Soil 51 degrees $-F=2.275, Q=9.41, A=0.610-$ radial synthesis

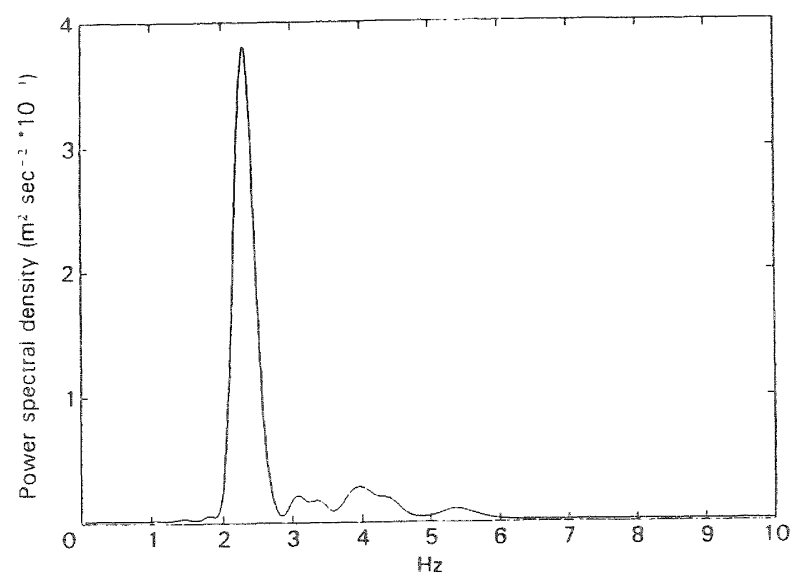

FIG. 11. SPECTRUM OF SYNTHETIC SOIL ACCELERATIONS AT 51. THE MODEL HAS A FREOUENCY OF $2.275 \mathrm{HZ}, \mathrm{A} Q$ FACTOR OF 9.41, AND AN AMPLITUDE FACTOR OF 0.610 AND IS DRIVEN BY RADIAL ROCK MOTION. NOTE THE ABSENCE OF THE MARKER PEAK.

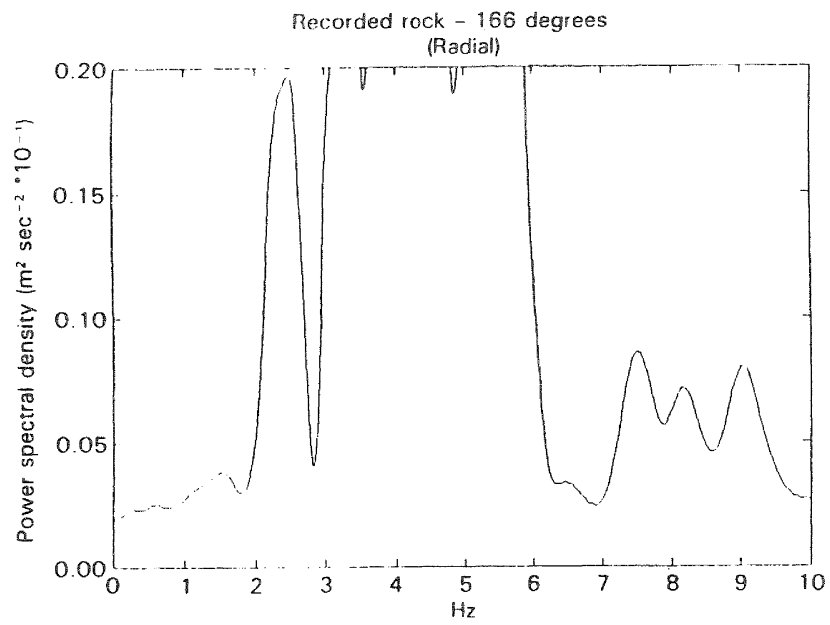

FIG. 13. SPECTRUM OF THE RECORDED RADIAL ROCK MOTION FOR THE $1 / 11 / 68$ EARTHOUARE. NOTE THE ABSENCE OF THE MARKER PEAK.
Recorded soil - 51 degrees

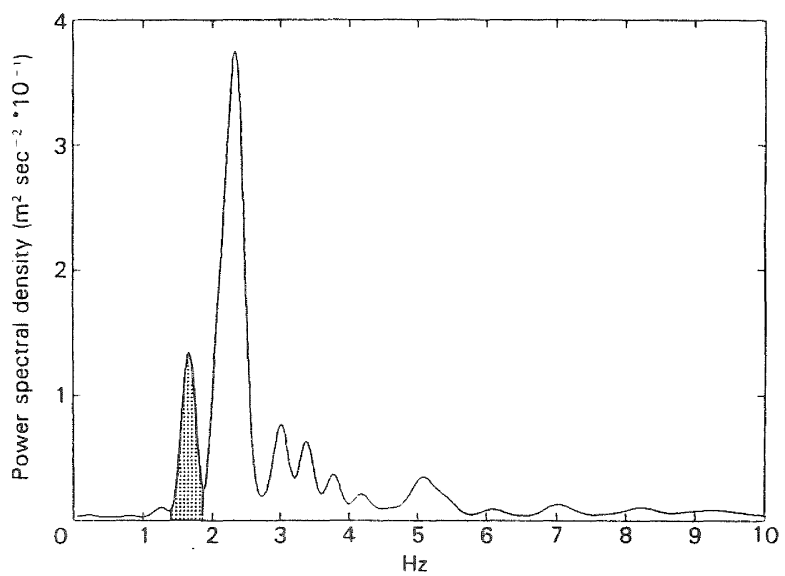

FIG. 10. SPECTRUM OF SYNTHETIC SOIL ACCELERATIONS AT 51\% THE MODEI HAS A FREOUENCY OF $2.147 \mathrm{HZ}, A$ Q FACTOR OF 10.39, AND AN AMPLITUDE FACTOR OF 1.573 AND IS DRIVEN BY TRANSVERSE ROCK MOTION. THE MARKER PEAK IS SHADED.

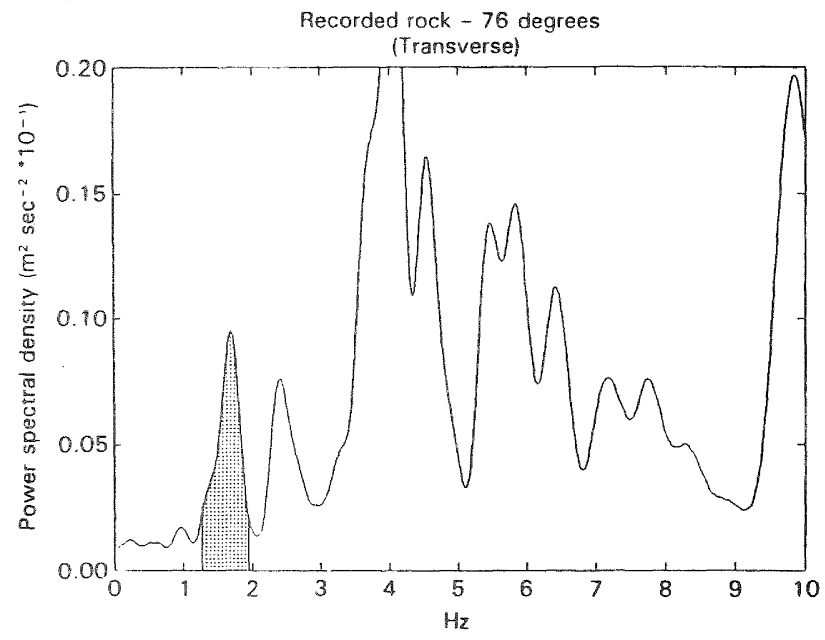

FIG. 12. SPECTRUM OF THE RECORDED TRANSVERSE ROCK MOTION FOR THE 1/11/68 EARTHOUAKE。 THE MARKER PEAK IS SHADED.

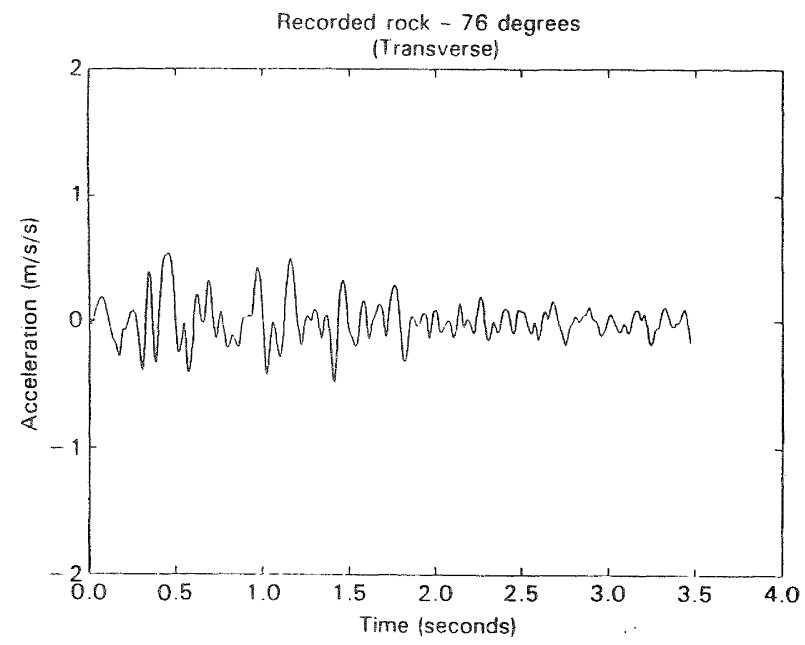

FIG. 14. RECORDED TRANSVERSE ROCK MOTION FOR THE 1/11/68 EARTHOUAKE. 
estimates of natural frequency and damping from the position of the resonant peak and its width at half height respectively. Once the damping is known, an amplitude factor can be estimated from the ratio of soil and rock power spectra at the resonant frequency.

It was found most convenient to obtain preliminary values for frequency, damping, and amplitude as above, and then to use the simplex algorithm [10] to seek an optimum set of frequency, damping (expressed as a $Q$ factor) and amplitude which matched the spectra of synthetic and recorded soil motions over the frequency range of the resonance. The simplex program was adapted from Caceci and Cacheris [11] and was coded to minimise the sum of squared differences between recorded and synthetic spectra, at $0.02 \mathrm{~Hz}$ intervals, between $1.64 \mathrm{~Hz}$ and 2.60 $\mathrm{Hz}$ (the resonant band). The method is detailed in Stephenson [12]. The optimum model had a frequency of $2.15 \mathrm{~Hz}$, a $\mathrm{Q}-$ factor of 10.4, and an amplitude factor of 1.57 .

When the transverse rock motion was convoluted with the impulse response of this model, the resultant waveform (Fig. 7) matched the recorded waveform in the resonant direction (Fig. 8), particularly at frequencies close to the resonance.

The same process was repeated, using the recorded radial rock motion to drive the resonator. The optimum model had a frequency of $2.275 \mathrm{~Hz}$, a Q-factor of 9.4, and an amplitude factor of 0.61 , and the synthesised waveform (not shown here) also matched the recorded resonant soil waveform well.

The model based on transverse rock motion input is preferred because it correctly predicts the peak (see Fig. 9) at $1.64 \mathrm{~Hz}$ in the spectrum of the recorded soil motion (see Fig. 10) while the model based on radial rock motion input does not (see Fig. 11). This peak functions as a natural marker of processes based on transverse motion because it is present in the incident rock motion for the transverse case (Fig. 12) but not for the radial case (Fig. 13).

The rock drive function may be a combination of the transverse and radial rock motions, which would pass the marker peak on to the recorded motions. If the soil resonator had a frequency close to $1.64 \mathrm{~Hz}$, a small amount of the transverse motion would serve to transmit the marker to the synthesised record. The rest of the drive would be composed of radial motion, and the drive function would be the rock motion component in a direction close to radial.

To test this possibility, the simplex algorithm was used to find the best combination of resonator frequency and amplitude (assuming a damping of $5 \%$ of critical $(0=10)$ ) and direction of drive component. This best fit resonator had a frequency of $2.14 \mathrm{~Hz}$ and an amplitude factor of 1.46 , driven at 79.7 degrees, 3.7 degrees from the transverse component.

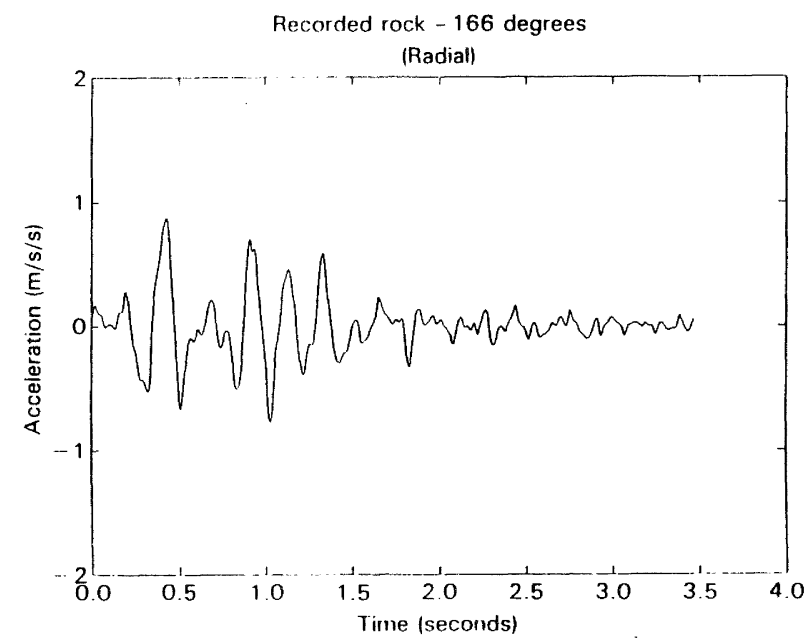

FIG. 15. RECORDED RADIAL ROCK MOTION FOR THE 1/11/68 EARTHQUAKE.

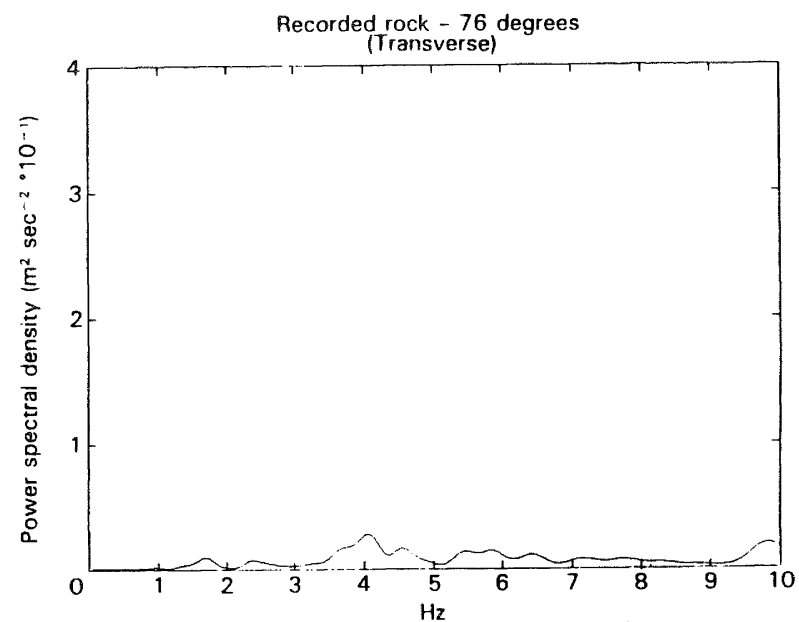

$\begin{array}{lllll}\text { FIG. } 16 . & \text { SPECTRUM } & \text { OF } & \text { THE } & \text { RECORDED } \\ & \text { TRANSVERSE } & \text { ROCK } & \text { MOTION } & \text { FOR THE }\end{array}$ $1 / 11 / 68$ EARTHQUAKE.

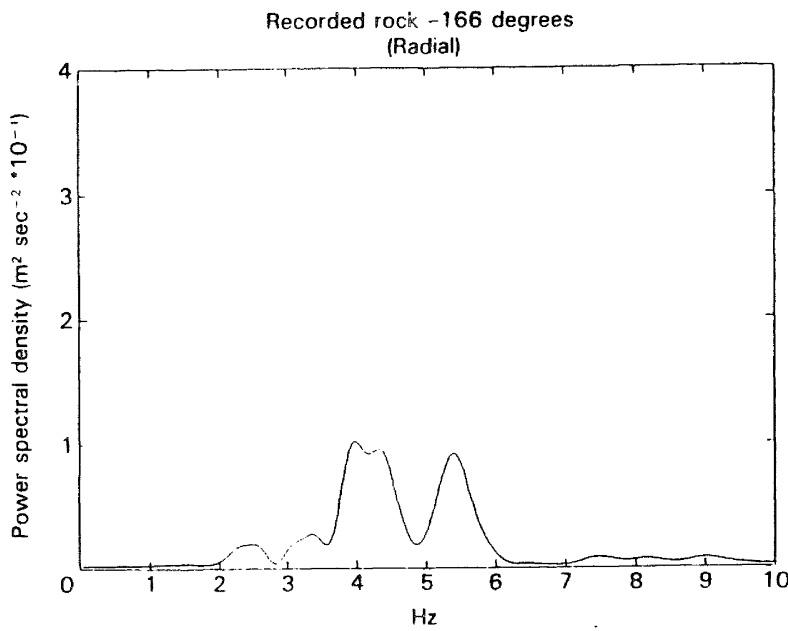

FIG. 17. SPECTRUM OF THE RECORDED RADIAI ROCK MOTION FOR THE $1 / 11 / 68$ EARTHQUAKE 
It would thus appear that the possibility of radial excitation does not exist, and that the best soil model is a resonator along $51^{\circ}$ driven by the transverse rock component, with the resonator having a frequency of $2.15 \mathrm{~Hz}$, a $Q$ factor of 10.4 , and an amplitude factor of 1.57. As seen by the match of recorded and synthesised time history waveforms (Figs. 7 and 8), this model certainly offers a good prediction for this earthquake, and confirms that excitation of a singledegree-of-freedom resonator by the transverse rock motion leads to the resonant soil motion.

The good predictive capacity of the model, and the close agreement of its resonator frequency with the seismic CPT derived frequency give strong support to the view that the post-glacial sediments of the lower Hutt Valley respond to earthquakes in accordance with the cellular mode response hypothesis.

The present model differs in several crucial respects from state of the art research models, and from the models which give rise to current engineering practice. Researchers have lost their early preoccupation with simple geometries and complex non-linear media e.g. Taylor and Larkin [13], and are now concentrating on two and three-dimensional geometries coupled with linear homogeneous media e.g. Bard and Bouchon [14], Sánchez-Sesma, Chávez-García and Bravo [15], Lee and Langston [16] and Jiang, Tong and Kuribayashi [17]. Though these models have more in common with the cellular mode model than early models none of them incorporate the idea of a directed response. The essential reasons for this are that in the case of [14], the incident waves propagate vertically, for [15] two-dimensional representations do not allow incompressible flow effects, for [16] the frequency of the exciting wave is inappropriate for a resonance, and for [17] the case of an incident $S$ wave was not studied. The methods of ${ }^{h}[17]$ seem ideally suited to this problem and if a basin $1 \mathrm{~km}$ in diameter and $20 \mathrm{~m}$ deep, filled with material of $150 \mathrm{~m} / \mathrm{s}$ shear wave velocity were chosen, and obliquely incident $S$ waves applied, results in agreement with the Hutt valley observations would be expected.

Because one-dimensional models can only treat the two horizontal components of motion independently they do not allow directional effects and are thus immediately at variance with the experimental results presented here and those presented by Stephenson [2] and Mena et al. [18] where strong directional effects are reported at many sites world wide. One-dimensional models are the foundation of procedures used in current engineering practice.

\section{FURTHER REMARKS}

The modelling described in this paper results from the need to predict earthquake motion on flexible soil, in order to mitigate earthquake damage to structures. However, the particular earthquake studied was not a very damaging one, and no amplification due to flexible soil was noted. Hence subtle features of the records had to be examined in order to establish that transverse motion excited the directed resonance.

Figures 14 to 17 provide evidence that the motion arriving via the rock is concentrated between $3.5 \mathrm{~Hz}$ and $6 \mathrm{~Hz}$ on the radial component. The transverse rock motion at $2.15 \mathrm{~Hz}$ is a very small proportion of the total motion.

An earthquake radiating a larger proportion of its energy as horizontal transverse motion at the soil resonant frequency would excite the resonance more. It is expected that the orientation of the causative fault and the mechanism of slip will govern which component is generated, and that the magnitude of the event will govern the spectrum of the radiated energy. Aki and Richards [19] give expressions for the radiation of waves from a double couple source equivalent to a fault slip. These expressions show that for a vertical fault plane and a $90^{\circ}$ take off angle (consistent with a distant shallow earthquake) a strike slip fault only radiates $S$ waves, and these are radiated at right angles to the fault direction. For the same fault, a dip slip only radiates $S$ waves, and these are preferentially radiated along the fault direction. As the fault plane departs from the vertical these simple relations progressively fail as the strike slip movement begins to radiate $S$ waves, and its $S_{\text {p }}$ pattern becomes quadrantal. similarly the dip slip movement begins to radiate $S$ waves as the fault plane departs from the hertical. These results enable us to see the circumstances which will lead to strong soil resonant responses. A strike slip along a vertical fault running parallel to the transverse direction would preferentially radiate transverse waves $\left(S_{h}\right)$, and if the source had a corner frequency less than the soil resonant frequency, the spectrum of the incident

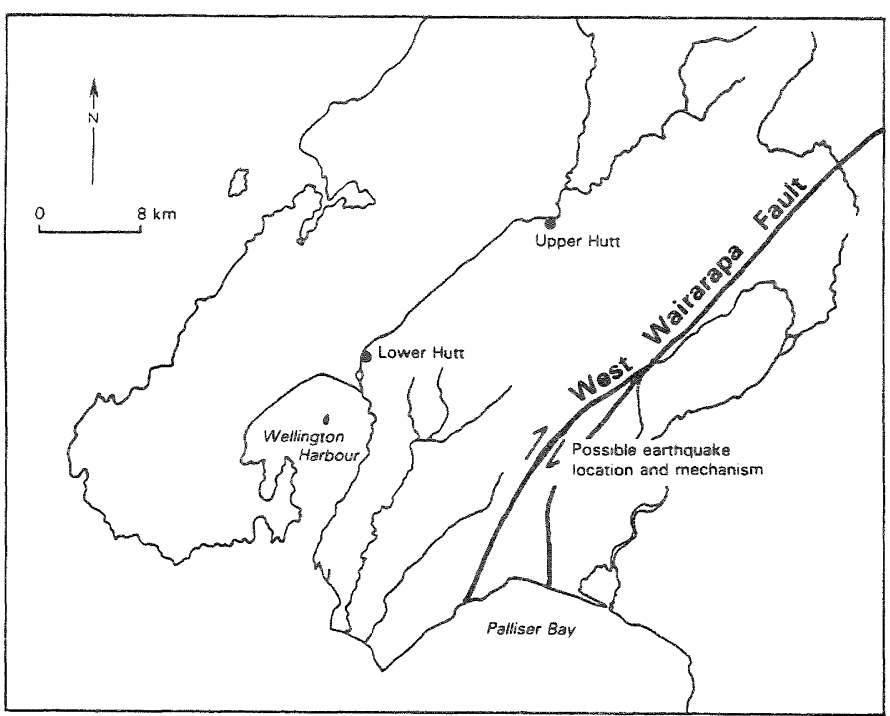

FIG. 18. AN EARTHQUAKE EPICENTRE AND MECHANISM WHICH WOUID RESULT IN GREAT EXCITATION OF THE GRACEFIELD CELI. 


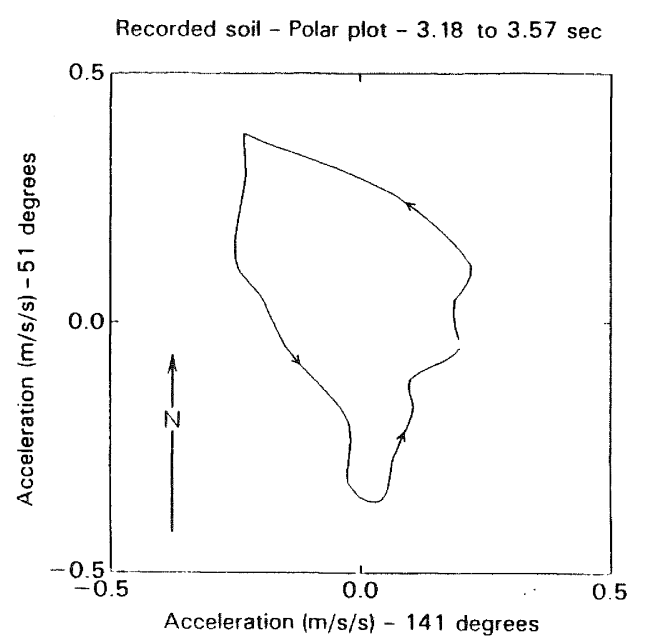

FIG. 19. POLAR PLOT OF HORIZONTAL SOII ACCELERATION FROM 3.18 SEC TO 3.57 SEC FOR THE $1 / 11 / 68$ EARTHQUAKE.

Recorded soil - Polar plot -3.57 to $3.94 \mathrm{sec}$

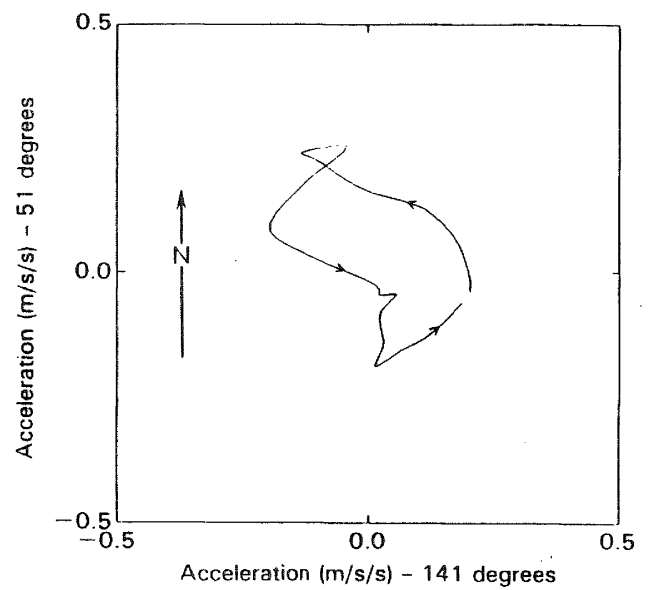

FIG. 20. POLAR PLOT OF HORIZONTAL SOIL ACCELERATION FROM 3.57 SEC TO 3.94 SEC FOR THE $1 / 11 / 68$ EARTHQUAKE.

Recorded soil - Polar plot -3.94 to $4.16 \mathrm{sec}$

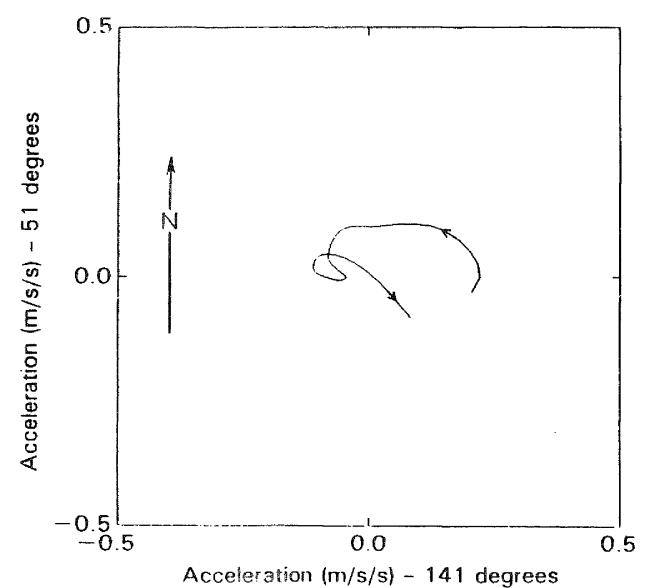

FIG. 21. POLAR PLOT OF HORIZONTAL SOIL ACCELERATION FROM $3.94 \quad$ SEC TO 4.16 SEC FOR THE $1 / 11 / 68$ EARTHQUAKE. wave would be rich in motion suitable for exciting the resonator. The corner frequency is determined by the surface wave magnitude $M$ or seismic moment [20] but generally dêcreases as earthquake magnitude increases.

The 1968 November 1 event of magnitude 5.4 produced a measurable resonant response on soil. Thus it is likely that an earthquake of magnitude greater than 6 , involving a strike slip on the West Wairarapa fault between Palliser Bay and Lake Wairarapa (Fig. 18), would prove very effective at exciting the Gracefield cell (see Fig. 6), and that buildings within this cell would suffer enhanced damage, particularly if they resonated at the soil resonant frequency. (Buildings of around five storeys high and of conventional construction would so resonate).

In the lower Hutt Valley, the wide extent of the flexible soil compared with its $22 \mathrm{~m}$ depth means that it is likely that there will exist several nearly degenerate modes, some of which may not be excited directly by an earthquake. The soil record of the 1968 November 1 earthquake after three seconds shows a feature which is consistent with another mode being excited indirectly. Figs. 19 to 21 are polar plots of the motion after three seconds, and they show decreasing anticlockwise ellipses whose axes also rotate anticlockwise. Such a motion can result from two modes being excited simultaneously, ninety degrees out of phase. The mechanism by which an undriven mode can obtain energy from a driven one is probably related to small nonlinearities in the soil stress-strain curve. The response of one mode can cyclically change the stiffness of the soil responding to another mode and increase the response of the latter by a process of parametric amplification. Tritton [21] analyses the motion of a simple pendulum, showing that the small nonlinearity in the force-angle characteristic of the pendulum leads to an interaction between two modes of resonance. The polar plots which he obtains bear a remarkable resemblance to those of Figs 19 to 21 of this paper. While such notion is quite in accord with the cellular normal mode hypothesis, the simultaneous action of several modes could be hard to interpret. Triton [21], describes such motion of the pendulum as chaotic - the motion cannot be predicted. If the soil motion in these circumstances is also chaotic no model will suffice to predict it. By studying areas of small extent-to-depth ratio it may be possible to avoid this complication, as near degeneracy will not be expected.

The relatively small magnitude of the earthquake used in this study constrains the frequency range of rock vibrations, and hence limits the resonators capable of being detected, to frequencies of over 1.5 $\mathrm{Hz}$. In principle an earthquake of greater magnitude could excite resonators of lower frequency. However, the next resonant unit is likely to be all the material (about 300 m depth) above bedrock, probably with a shear wave velocity of over $1 \mathrm{~km} / \mathrm{sec}$ and consequently resonating at greater than 0.8 $\mathrm{Hz}$. It is very Iikely that the resonance treated in this paper will prove to be the only significant soil effect. 


\section{CONCLUSION}

Ground motion on the flexible soils at the Physics and Engineering Laboratory DSIR, during the cook strait earthquake of 1968 November 1, was consistent with the oscillating fluid flow behaviour of a cellular resonant mode, excited by the transverse component of rock motion crossing the area of the cell. Rapid horizontal propagation of this transverse component through the rock under the soil, and slow vertical propagation through the soil, result in the large-scale horizontal shear and small- scale vertical shear needed to excite a cellular mode of resonance effectively.

The observed effect was small because the cook strait earthquake had a small transverse component, and radiated little energy at the natural frequency of the mode because of its small magnitude. However, for a large earthquake involving strike slip movement along a fault oriented orthogonal to a line to the flexible soil, excitation of the mode is expected to be large, and damage, especially to resonant structures, is expected to be much greater on these flexible soils than on rock.

\section{REFERENCES}

1. Kerr, R.A., 'Predictable Quake Damage', Science, V. 230, No. 4726 , Nov. 8, 1985, p. 653.

2. Stephenson, W.R., 'Cellular Normal Modes of Alluvium Response' Bulletin of New Zealand National Society for Earthquake Engineering, $V$. 8, No. 4, Dec. 1975, pp. 245-254.

3. Stephenson, W.R., 'Normal Modes of a "Cylindrical Valley" of Alluvium', Bulletin of New Zealand National Society for Earthquake Engineering. This issue.

4. Stevens, G.R., 'Hutt Valley Artesian System", New Zealand Journal of Science and Technology, V.38, section B, No. 3, Nov. 1956, pp.149-156.

5. Stevens, G.R., 'Hutt Valley Stratigraphy', New Zealand Journal of Science and Technology, V.38, section B, No. 3, Nov. 1956, pp.201-235.

6. Stevens, G.R., 'Geomorphology of the Hutt Valley', New Zealand Journal of Science and Technology, V.38, section B, No. 4, Jan. 1957, pp. 297-327.

7. Robertson, P.K., Campanella, R.G., Gillespie, D. and Rice, A., 'Seismic CPT to Measure In Situ Shear Wave Velocity'. Journal of Geotechnical Engineering, V. 112, No. 8, Aug. 1986, pp.791-803.

8. Stephenson, W.R. and Barker, P.R., 'A Seismic CPT Probe at Petone', NZ Soil Bureau Laboratory Report EP25, Department of Scientific and Industrial Research, New Zealand, 1988
9. Sanglerat, G., 'The Penetrometer and Soil Exploration', Elsevier, Amsterdam, 1972 .

10. Nelder, J.A. and Mead, R., 'A Simplex Method for Function Minimization', Computer Journal, V.7, 1965, pp.308-313.

11. Caceci, M.S. and Cacheris, W.P., 'Fitting Curves to Data. The Simplex Algorithm is the Answer', Byte, V.6, No.5, May 1984, pp. 340-362.

12. Stephenson, W.R., 'Procedures and Programs used to Process Earthquake Accelerograms', NZ Soil Bureau Laboratory Report EP 26 , Department of Scientific and Industrial Research, New Zealand, 1988.

13. Taylor, P.W. and Larkin, T.J., 'Seismic Site Response of Nonlinear Soil Media, Journal of the Geotechnical Engineering Division, ASCE, V.GT3, March 1978, pp. 369-383.

14. Bard, P. and Bouchon, M., 'The Seismic Response of Sediment-filled Valleys. Part 1. The case of Incident $S_{\text {}}$ Waves', Bulletin of the seismological Society of America, v.70, No.4, August 1980, pp. 1263-1286

15. Sánchez-Sesma, F.J., Chávez-García, F.J. and Bravo, M.A., 'Seismic Response of a Class of Alluvial Valleys for Incident $S$ Waves', Bulletin of the Seismological society of America, V.78, No. 1, February 1988, pp. 83-95.

16. Lee, J. and Langston, C.A., 'Wave Propagation in a Three-Dimensional Circular Basin', Bulletin of the Seismological Society of America, V.73, No. 6, December 1983, pp. 1637-1653.

17. Jiang, Tong and Kuribayashi, E., 'The Three-Dimensional Resonance of Axisymmetric Sediment-filled Valleys', Soils and Foundations, V. 28, No. 4, December 1988, pp. 130-146.

18. Mena, E., quaas, R., Prince, J., Almora, D., Pérez, P., Carmona, C., Torres, M., Delgado, R., Chávez, G. Alcántara, L. and oñate, M. , 'Acelerograma en el centro SCOP de la Secretaria de Comunicaciones y Transportes. Sismo del 19 de Septiembre de 1985', Informe IPS-10B, Instrumentación Sísmica, Instituto de Ingeniería, UNAM, Mexico.

19. Aki, K. and Richards, P.G., 'Quantitative Seismology. Theory and Methods', W.H. Freeman and Co., San Francisco, 1980.

20. Kasahara, K., 'Earthquake Mechanics', Cambridge University Press, 1981.

21. Tritton, D., 'Chaos in the swing of a Pendulum', New Scientist, V.111, No.1518, July 24, 1986, pp.37-40. 